\title{
ANÁLISE COMPARATIVA DE RESULTADOS ENTRE AS CULTURAS DE SOJA, MILHO E PRODUÇÃO LEITEIRA EM UMA PEQUENA PROPRIEDADE RURAL
}

Raquel Sabrina Zappe ${ }^{1}$

Euselia Paveglio Vieira ${ }^{1}$

Ana Paula Da Rosa Dezordi ${ }^{1}$

Ariosto Sparemberger ${ }^{1}$

${ }^{1}$ Universidade Regional do Noroeste do Estado do Rio Grande do Sul 


\section{ANÁLISE COMPARATIVA DE RESULTADOS ENTRE AS CULTURAS DE SOJA, MILHO E PRODUÇÃO LEITEIRA EM UMA PEQUENA PROPRIEDADE RURAL}

Resumo: A contabilidade rural é uma importante ferramenta para a agricultura, por meio das informações fornecidas pela contabilidade de custos aliadas a indicadores econômicofinanceiros, os empresários rurais conseguem utilizá-las para a tomada de decisão em suas propriedades. O objetivo do estudo é analisar os indicadores de resultados da cultura de soja, milho e atividade leiteira de uma propriedade de pequeno porte localizada na região Noroeste do Estado do Rio Grande do Sul e propor a combinação das atividades que resultam o melhor resultado para a mesma. O estudo tem como base os custos diretos, indiretos, fixos e variáveis das três atividades, soja, milho e leite, os mesmos foram classificados e analisados em uma comparação de um hectare. Em comparação a atividade leiteira apresentou o maior resultado, maior margem de contribuição, melhor ponto de equilíbrio e melhor margem de segurança operacional, e o investimento de $\mathrm{R} \$ 130.600,00$, realizados pela propriedade nas três atividades são recuperados em nove anos e dois meses. Concluiu-se que para a propriedade alcançar os mesmos resultados da atividade leiteira, necessita no mínimo cultivar onze hectares de soja e trinta e seis hectares de milho.

Palavras-chave: Agricultura. Custo. Margem. Viabilidade.

\section{Introdução}

De acordo com os professores Davis e Goldberg (1957), agribusiness se compõem do conjunto das operações de produção e distribuição de suprimentos agrícolas, das operações de produção nas fazendas, armazenamento, processamento e distribuição dos produtos e itens produzidos a partir deles. Isto possibilitou a compreensão de negócios agrícolas como um conjunto de agentes envolvidos nos processos de transformação e adição de valor às mercadorias agrícolas.

O IBGE (2006) relata que no Brasil, o número de estabelecimentos que produzem soja é de 215.977, produzindo 40.712.683 milhões de toneladas, considerando uma área colhida de 15.646.980 milhões de hectares. O número de estabelecimentos que produzem milho é de 2.030.122 milhões, produzindo 42.281 .800 milhões de toneladas, considerando uma área colhida de 11.724.362 milhões de hectares. O número de estabelecimentos que possuem produção leiteira é de 1.349.326 milhões, com 12.636.548 milhões de vacas ordenhadas e produzindo 20.157 .682 bilhões de litros de leite.

De acordo com a EMATER/RS - ASCAR (2017), o Estado do Rio Grande do Sul apresentou no ano de 2016 uma área colhida para a cultura de soja de 5.436.653 de hectares, com produção de 16.209.892 toneladas. No Estado, a cultura de milho apresentou uma área de 738.370 hectares, com produção de 4.729 .948 de toneladas. Na atividade leiteria o Estado do Rio Grande do Sul apresentou uma produção de 4.613 .780 bilhões de litros de leite.

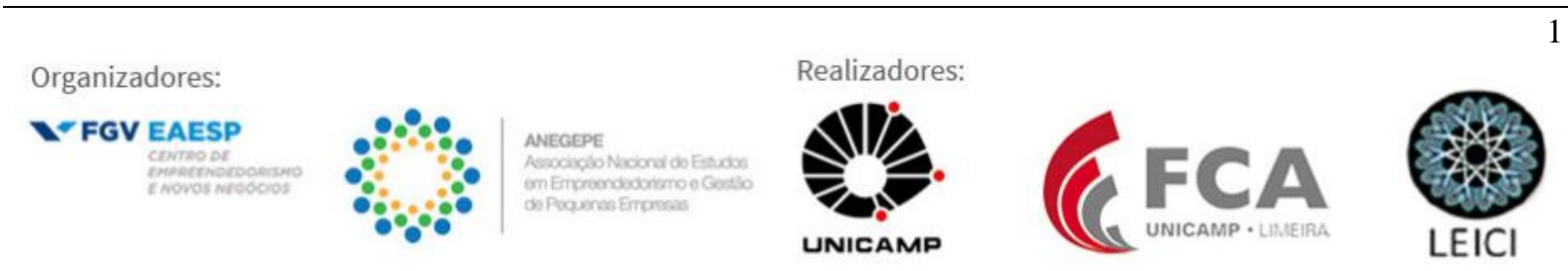


Neste sentido, o estudo visa elaborar uma análise da produção de soja, milho e leite, em uma propriedade denominada ficticiamente como Fazenda ZP, a mesma possui 30 hectares para cultivo, se enquadrando em pequeno porte, situa-se na região noroeste do Estado do Rio Grande do Sul.

Para analisar a produção foi necessário o estudo dos custos diretos e indiretos, por hectare e total de cada cultivar e da produção leiteira, calculou-se a receita e com isso, tem-se o resultado da propriedade por hectare e por saca no caso das cultivares soja e milho e em litros no caso da produção leiteira. Baseado nesses dados efetuou-se a apuração da margem de contribuição unitária e total, do ponto de equilíbrio e da margem de segurança operacional da propriedade, seguido dos indicadores Valor Presente Líquido (VPL), do Tempo Interno de Retorno (TIR), da Taxa Mínima de Atratividade (TMA) e do Payback descontado.

Levando-se em consideração a proposta de estudo, a questão problema é: Como a análise dos resultados, dos indicadores de cada atividade pode diferenciar a gestão da propriedade na definição das mesmas? Sendo que, o objetivo do estudo é analisar os indicadores de resultados de cada cultura e propor a combinação das atividades que proporcionam o melhor resultado a propriedade.

O estudo justifica-se em construir um diagnóstico para os agricultores, tanto na gestão quanto organização de suas propriedades, não basta somente possuir informações, mas sim saber interpretá-las, com o auxílio da contabilidade rural, de custos e com os indicadores de viabilidade econômico-financeira, os quais são imprescindíveis para verificar e reorganizar a propriedade para que gere a melhor alternativa, dentre as atividades que a propriedade possui, ou até mesmo, inserir outras culturas ainda não cultivadas pela propriedade.

É nesse sentido, que esse artigo se justifica, a partir de estudos já realizados em outros Estados do Brasil, aplicar e avaliar como é o comportamento no desempenho Econômico dessas três atividades desenvolvidas na propriedade, contribuindo com os gestores nas decisões de investimentos e de gerenciamento da mesma.

\section{Referencial Teórico}

\subsection{Contabilidade Rural}

Com o setor agrícola em expansão pela mecanização, tecnologia e modernização aplicadas nesta atividade, os custos aumentam, os proprietários rurais necessitam de mais controle para gerenciar suas propriedades. Segundo Hall et al., (2008) com o advento da tecnologia, a produtividade das propriedades rurais está cada vez mais acelerada, a demanda do seu gerenciamento por meio da contabilidade é cada vez mais notória pelos gestores das propriedades.

Para Suski; Braum e Braun (2014) as empresas rurais estão vivenciando uma nova realidade, produzir mais em menor espaço, a partir dessa realidade, as empresas precisam estar organizadas para gerenciar seus resultados, para isso, a contabilidade rural vem de encontro como instrumento de apoio, controle e planejamento.

Neste sentido, Hofer e Huppes (2007) salientam que a contabilidade tem papel fundamental nas empresas rurais, por intermédio de seus demonstrativos, como por exemplo, Balanço Patrimonial e a Demonstração do Resultado do Exercício que ajudam os gestores das
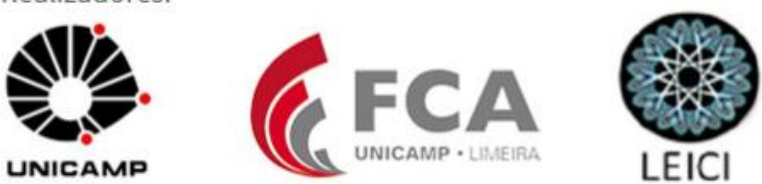
propriedades alcançarem seus objetivos traçados. Baseando-se nela, os custos, despesas, gastos e todo o patrimônio são demonstrados e controlados, fornecendo informações importantes para a gerência da propriedade, importante fator para o andamento da entidade na questão financeira e de planejamento.

Portanto, com a contabilidade inserida na atividade rural os proprietários verificam que analisar os custos e saber medi-los, controla-los e racionaliza-los é essencial para esse ramo de atividade, e ainda, obter informações gerenciais por meio dos sistemas da contabilidade de custos na atividade rural é necessário para o bom andamento do negócio.

\subsection{Contabilidade de custos}

$\mathrm{Na}$ atualidade, a globalização e o avanço tecnológico estão cada vez mais presentes nas empresas rurais, influenciando na produtividade, na forma e quantidade de serviços, maquinários, mão-de-obra e tantas outras mudanças. De encontro com esses avanços a contabilidade tem papel fundamental para organizar, mensurar, controlar e gerir informações relevantes para as empresas rurais.

Suski; Braum e Braun (2014) salientam que com a globalização, a produção de alimentos mundial sofre mudanças, e o constante aumento dos mercados para a produção de alimentos faz com que cada vez mais as propriedades rurais tenham como alicerce a contabilidade rural, na qual as informações relevantes são extraídas para os usuários das mesmas aplicarem na gestão de seus empreendimentos.

$\mathrm{Na}$ contabilidade, os custos classifica-se em: custos diretos, custos indiretos, custos fixos e custos variáveis. A classificação dos custos é de suma importância, em função de que cada entidade possui suas atividades, assim, as informações, os usuários que utilizaram as mesmas e os níveis de complexidade são diferentes. A partir da correta classificação dos custos, as informações, a tomada de decisão e os controles são organizados de acordo com a realidade da empresa, (SILVA; LINS, 2010).

Custos diretos para Santos; Marion e Segatti (2002) são aqueles que são identificados diretamente no produto acabado, como por exemplo, litros de agrotóxicos; quilos de sementes adubos ou rações; hora de mão-de-obra; gastos com manutenção dos maquinários; portanto, os mesmos são classificados com exatidão no produto. Já os custos indiretos, são aqueles que não possuem perfeita identificabilidade nos produtos, não podendo ser feita a apropriação direta para o produto, por esse motivo, necessitam de algum critério de rateio para a correta alocação dos mesmos, (PEREZ JR; OLIVEIRA, COSTA, 2001).

Para Silva e Lins (2010) custos fixos são aqueles que no seu total não variam proporcionalmente ao volume produzido, independentemente da quantidade produzida pela entidade, o custo fixo total não sofrerá variação. Já os custos variáveis possuem relação direta com o volume da produção da empresa, assim, a quantidade da produção reflete no custo do produto.

Os métodos de custeio têm o objetivo de verificar o custo unitário de cada produto ou serviço, eles também possuem uma classificação, eles são dois: por absorção e variável. Para Souza e Clemente (2011) o custeio por absorção é aquele que os custos diretos e indiretos utilizados para produzir o produto integram o custo do produto, assim, se as entidades produzirem mais de um produto os custos indiretos sofrem rateios para que os mesmos
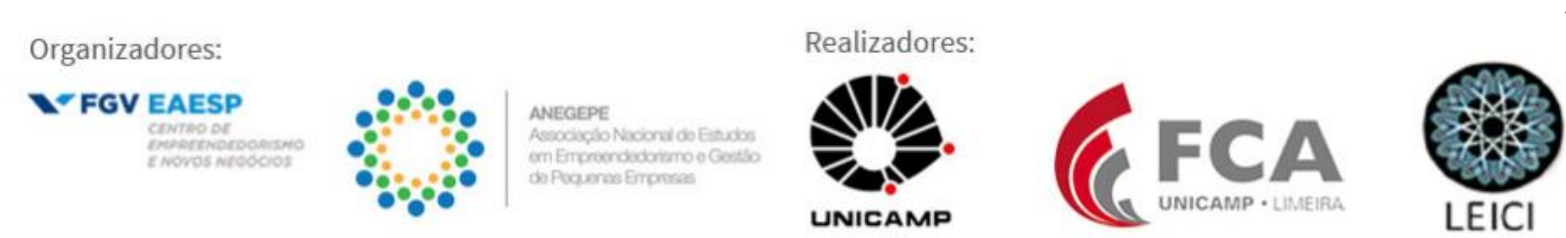
integrem todos os produtos produzidos. Finalizando, Martins (2001) relata que no custeio variável só são considerados os custos variáveis aos produtos, os custos fixos são considerados como despesa.

Para gerenciar os custos, volumes e resultados de uma empresa rural são necessários a utilização de fórmulas que fornecem informações importantes para o gerenciamento da empresa.

A margem de contribuição unitária segundo Santos; Marion e Segatti (2002) é diferença entre a receita bruta e custos e despesas variáveis, permitindo conhecer a alocação dos custos variáveis e a eficiência dos recursos diretos, ela pode ser unitária ou total.

De acordo com Padoveze (2003), o ponto de equilíbrio é a quantidade que cada entidade precisa produzir/vender para cobrir todos os custos e despesas fixas e variáveis, portanto ele é nulo, com produção adicional a entidade opera no lucro, ao contrário opera no prejuízo.

A margem de segurança operacional indica quanto a entidade deve vender a mais do que o indicado pelo ponto de equilíbrio. (Silva; Lins, 2010).

Com todas as mudanças que a zona rural está vivenciando é importante que mesmo sendo de forma simples, controles e planejamento sejam efetuados. Magro et al., (2011) compreende que não se precisa de técnicas modernas para aumentar a produtividade, controles simples dos custos de produção são essenciais para que o empresário rural gerencie sua produtividade para que seus resultados sejam alcançados.

\subsection{Indicadores de Análise Econômico-Financeira}

$\mathrm{Na}$ atividade rural em constante expansão e presente em muitas mudanças, necessitase que os agricultores tenham além de gestão de custos, a gestão econômico-financeira no gerenciamento de suas propriedades, por meio delas as informações podem ser geradas e as decisões podem ser tomadas, com os indicadores de valor presente líquido (VPL), taxa interna de retorno (TIR), taxa mínima de atratividade (TMA) e payback, pode-se verificar a análise dos investimentos e o tempo de retorno do capital, e com isso nortear estratégias para melhorar a produtividade da propriedade.

Para Kassai et al., (2000) o valor presente líquido é um dos instrumentos que avalia investimentos de capital, é medido pela diferença entre o valor presente das entradas e saídas de caixa, considerando uma taxa de desconto.

Já a taxa interna de retorno calcula a taxa de retorno do investimento em um projeto, ou seja, determina o percentual de quanto rende o projeto em análise. Assim consiste em uma taxa de desconto de um fluxo de caixa que zera seu valor presente líquido. Na análise de investimentos, a TIR é considerada atrativa quando a taxa interna de retorno for maior ou igual à taxa mínima de atratividade, e quando a taxa interna de retorno for calculada a partir de um fluxo de caixa descontado é atrativa quando é maior ou igual a zero. (KASSAI, 2000).

A TMA é a taxa que estipula o valor mínimo que um investimento deve gerar. Ela é norteada pelas principais taxas de juros que são aplicadas pelo mercado, é essencial na análise de viabilidade de um projeto, ela é comparada com a taxa interna de retorno, com base na análise comparativa dessas duas taxas, é possível verificar se o projeto vai resultar em uma TIR maior ou menor do que o mínimo estipulado pela TMA.
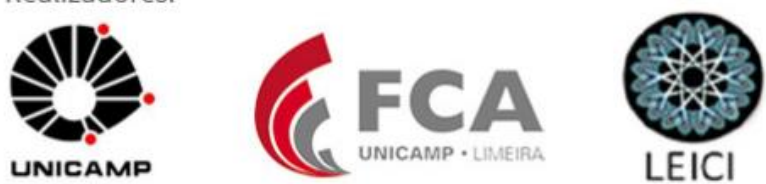
Já payback fornece o tempo que vai levar para recuperar o montante investido em um projeto, ou seja, é o tempo que se precisa para que o lucro acumulado se iguale ao investimento inicial, esse tempo pode ser dado por dias, meses e anos. "O payback é o período de recuperação de um investimento e consiste na identificação do prazo em que o montante do dispêndio de capital efetuado seja recuperado por meio dos fluxos líquidos de caixa gerados pelo investimento. [...]”. (KASSAI, 2000, p.84). Gitman (2010, p.366) contribui com: “[...] O período de payback é o tempo necessário para que a empresa recupere o investimento inicial em um projeto, calculado a partir das entradas de caixa. [...]".

\section{Método}

A metodologia é a via estrutural para a realização da pesquisa. Como o estudo busca analisar os indicadores de resultados das culturas de soja, milho e da produção leiteira de uma propriedade rural e propor a combinação das atividades que proporcionam o melhor resultado a propriedade, a classificação da pesquisa é aplicada. Silva e Menezes (2005, p.20) conceituam: "[...] Pesquisa aplicada objetiva gerar conhecimentos para aplicação prática e dirigidos à solução de problemas específicos. Envolve verdades e interesses locais.”. Assim, neste estudo, utilizou-se a pesquisa aplicada, como é um assunto que já foi criado e estudado, busca-se aprofundar os estudos nesta área.

Do ponto de vista de seus objetivos, a pesquisa é classificada como descritiva, porque utilizou-se dos métodos padronizados de coleta de dados, com base na aplicação da entrevista despadronizada e da observação sistemática aos proprietários da empresa rural.

Quanto a abordagem do problema, o estudo é qualitativo. De acordo com Beuren et al., (2004) na pesquisa qualitativa concebem-se análises mais profundas em relação ao fenômeno que está sendo estudado. Os procedimentos técnicos para a coleta de dados utilizados neste estudo são a pesquisa bibliográfica, utilizando-se de diversas bibliografias e publicações já existentes sobre o assunto.

Pesquisa documental, conforme Marconi e Lakatos (2003, p.174) "[...] a fonte de coleta de dados está restrita a documentos, escritos ou não, constituindo o que se denomina de fontes primárias. Estas podem ser feitas no momento em que o fato ou fenômeno ocorre, ou depois". O estudo de caso se realizará em uma propriedade rural, onde todas as notas fiscais, blocos do produtor rural e documentos pertinentes são analisados para a coleta de dados.

Pesquisa levantamento, na qual os dados foram coletados por meio de entrevista despadronizada realizada com os proprietários do empreendimento rural nos meses de agosto a novembro do ano de 2017 correspondendo as informações das safras de soja, milho e produção leiteira do ano de 2016/2017.

A pesquisa é estudo de caso, por se tratar de apenas uma única propriedade rural em estudo, nela foram utilizados os instrumentos de coleta de dados, observação sistemática, individual e na vida real da propriedade rural. Antes da análise dos dados, foi aprofundado o estudo do referencial teórico, onde é comtemplado, a contabilidade rural, contabilidade de custos e os indicadores econômico-financeiros. Após, foi selecionada pelo critério de acessibilidade, uma propriedade para levantar e coletar os dados necessários para o estudo e pela análise documental e entrevista despadronizada da propriedade rural, os mesmos foram transferidos para uma planilha de Excel, onde pode-se analisar os custos, onde os mesmos

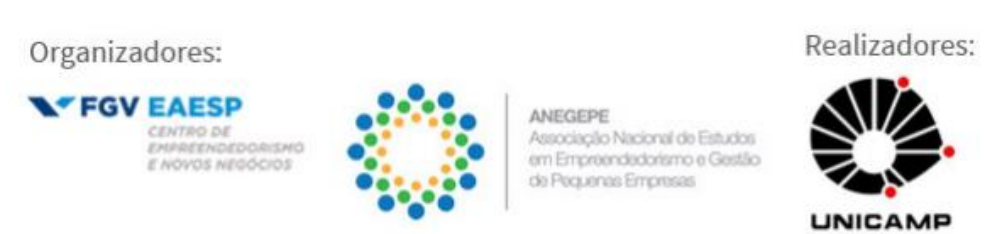

UNICAMP
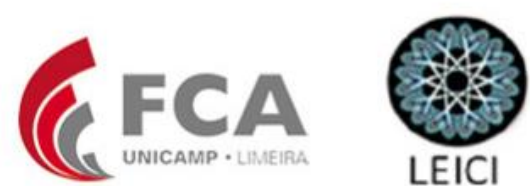
foram sistematizados, interpretados e apresentados, demonstrando os resultados das produções e os indicadores gerenciais, após foram efetuados os cálculos dos indicadores econômico-financeiros de cada atividade desenvolvida na entidade, para realizar a análise de viabilidade das mesmas, o objetivo principal desta pesquisa.

\section{Resultados e Discussão}

A agricultura é um setor muito importante para toda a cadeia, é a partir dela que ocorre o abastecimento de alimentos no mercado interno e o fluxo das movimentações do mercado externo. De acordo com o Censo Agropecuário do IBGE (2006) mais que $84 \%$ dos estabelecimentos agropecuários são oriundos de grupos familiares, constituindo $35 \%$ do PIB nacional.

Visto a importância do agronegócio, a propriedade em estudo é composta pela agricultura familiar, denominada ficticiamente por Fazenda ZP, propriedade de pequeno porte localizada no noroeste do Estado do Rio Grande do Sul, onde a média de hectares produzidas pelos agricultores compreende basicamente em até 50 hectares. Nela cultiva-se em uma área total de 30 hectares, soja, milho e produção leiteira, sendo que para cada atividade é destinado 10 hectares.

\subsection{Custos da propriedade}

Com a realização da entrevista despadronizada, levantou-se os dados referentes aos custos unitários e totais que a propriedade possui com as plantações de soja, milho e produção leiteira.

Cabe salientar, que a plantação de soja iniciou-se em agosto de 2016 e a colheita realizou-se em janeiro 2017, para o milho a plantação iniciou-se em novembro de 2016 e a colheita realizou-se em abril de 2017. Para a produção leiteira se possui o total de vinte vacas produtoras, sendo a raça predominante Jersey e Holandesa, no decorrer do ano, aproximadamente dez vacas entram no ciclo reprodutivo, estas, ficando de dois a três meses sem produzir leite.

Assim, como ambas cultivares possuem seis meses de duração, desde o plantio até a colheita, os custos da soja e do milho foram calculados nestes seis meses, para comparar de igual forma, os custos do leite também são deste mesmo período, considerando o período de outubro de 2016 a março de 2017.

No quadro 01 verifica-se os custos variáveis, fixos e totais de cada atividade realizada pela Fazenda ZP, nota-se que os custos mais expressivos são os custos variáveis, dentre eles os custos diretos apresentam maior representatividade, os quais são representados pelos insumos, estes que originam a colheita.

Na cultura da soja, a semente e o fertilizante são os custos mais expressivos dentre os custos diretos variáveis, representando $41 \%$ de custo com semente, no valor de R $\$ 3.006,84$ e $38 \%$ com custo de fertilizante, no valor de $\mathrm{R} \$ 2.775,00$.

Na cultura do milho ocorre a mesma situação, os custos diretos variáveis ganham destaque para a semente com $54 \%$ e para os fertilizantes adubo e ureia correspondendo ambos em $18 \%$, nos valores de $\mathrm{R} \$ 8.409,36, \mathrm{R} \$ 2.756,00$ e $\mathrm{R} \$ 2.794,50$ respectivamente. Assim percebe-se que os custos diretos variáveis do milho são duas vezes mais que a soja, isso
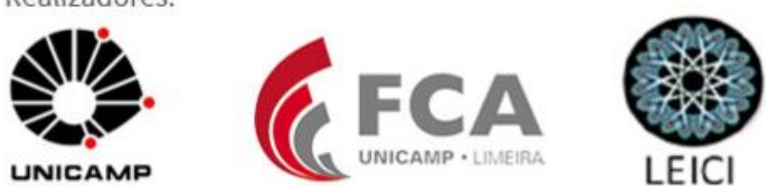
porque o custo da semente para o plantio é mais custosa que a da soja, e a cultivar milho necessita de uma adubação adicional que é a adubação nitrogenada (ureia), fazendo com que impacte nos custos totais desta cultura.

$\mathrm{Na}$ atividade leiteira o custo direto mais representativo é a ração, um dos principais alimentos para os animais produtores de leite, correspondendo $41 \%$, no valor de $\mathrm{R} \$ 7.240,80$ seguido do custo com silagem e pastagem correspondendo a $14 \%$ e $8 \%$ respectivamente, nos valores de $\mathrm{R} \$ 2.491,84$ e $\mathrm{R} \$ 1.448,93$ respectivamente.

Os custos indiretos variáveis também são representativos, na cultura da soja e do milho, os mais expressivos são os custos com o serviço da colheita, com 59\% na soja e 53\% no milho e custos com manutenção de máquinas, equipamentos e implementos, com $14 \%$ na soja e $16 \%$ no milho. $\mathrm{Na}$ atividade leiteira os custos indiretos mais representativos são os materiais de higiene da ordenhadeira e resfriador com $18 \%$ e manutenção das instalações com $13 \%$.

Os custos fixos apresentam baixa representatividade no total dos custos, eles são representados pelos custos com depreciação, impostos, taxas e contribuições, sendo que destes a depreciação que se destaca com maior valor, sendo $\mathrm{R} \$ 2.572,19$ para a cultura da soja, $\mathrm{R} \$ 1.336,09$ para o milho e $\mathrm{R} \$ 1.708,09$ para o leite.

Quadro 01 - Composição do Custo Unitário e Total - Produção 2016/2017

\begin{tabular}{|c|c|c|c|c|c|c|}
\hline \multicolumn{7}{|c|}{ Custo unitário e total em R\$ } \\
\hline Descrição & Soja & $\%$ & Milho & $\%$ & Leite & $\%$ \\
\hline Custos diretos variáveis & $7.366,76$ & $43 \%$ & $15.511,03$ & $64 \%$ & $17.865,83$ & $78 \%$ \\
\hline Custos indiretos variáveis & $7.151,46$ & $42 \%$ & $7.550,90$ & $31 \%$ & $3.337,38$ & $15 \%$ \\
\hline Total custos variáveis & $14.518,22$ & $85 \%$ & $23.061,93$ & $94 \%$ & $21.203,21$ & $92 \%$ \\
\hline Total custos fixos & $2.589,52$ & $15 \%$ & $1.353,43$ & $6 \%$ & $1.725,43$ & $8 \%$ \\
\hline Custo total & $17.107,74$ & $100 \%$ & $24.415,36$ & $100 \%$ & $22.928,64$ & $100 \%$ \\
\hline Produção sacas/litros & \multicolumn{2}{|l|}{500} & \multicolumn{2}{|l|}{1.200} & \multicolumn{2}{|l|}{33.899} \\
\hline Custo total por saca/litros & \multicolumn{2}{|c|}{34,22} & \multicolumn{2}{|c|}{20,35} & \multicolumn{2}{|l|}{0,68} \\
\hline Total de há produzidas & \multicolumn{2}{|l|}{10} & \multicolumn{2}{|l|}{10} & \multicolumn{2}{|l|}{10} \\
\hline Custo total por hectare & \multicolumn{2}{|c|}{$1.710,77$} & \multicolumn{2}{|c|}{$2.441,54$} & \multicolumn{2}{|c|}{$2.292,86$} \\
\hline
\end{tabular}

Fonte: Dados extraídos da pesquisa realizada (2017)

Levando-se em consideração o custo total, pode-se analisar que os custos variáveis são mais representativos que os custos fixos nas três atividades, na cultura de soja os custos variáveis representam $85 \%$ e os custos fixos $15 \%$, na cultura de milho $94 \%$ e $6 \%$ e na produção de leite $92 \%$ e $8 \%$ respectivamente. Isso ocorre pelos custos variáveis serem representados pelos custos com insumos, manutenção de máquinas, equipamentos e implementos e colheita tanto na cultura da soja, como na cultura do milho, e no caso do leite com ração, manutenção e higiene, custos estes que são elevados.

Dentre as três culturas, a cultura de milho apresentou o custo total mais representativo, com $\mathrm{R} \$ 24.415,36$, isto porque o custo variável com insumo é o mais elevado se comparado com as outras duas atividades, o milho é plantado com semente que possui melhoramentos genéticos cada vez mais constantes, combatentes a pragas e fungos, o que encarece o custo, mas em contrapartida reflete na produtividade, também possui a segunda adubação que é a ureia, necessária para o crescimento e fortalecimento da planta.

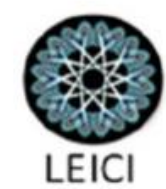


A produção da soja foi de 50 sacas por hectares, de milho 120 sacas por hectare e na atividade leiteira, em seis meses a produção foi de 33.899 litros de leite. Portanto, o custo da saca de soja é de $\mathrm{R} \$ 34,22$, de milho $\mathrm{R} \$ 20,35$ e do litro de leite $\mathrm{R} \$ 0,68$.

Pode-se observar também o custo total por hectare, na cultivar soja $\mathrm{R} \$ 1.710,77$, na cultivar milho $\mathrm{R} \$ 2.441,54$ e na atividade leiteira $\mathrm{R} \$ 2.292,86$. O custo total por hectare mais expressivo continua sendo para a cultivar milho, isto se justifica pela necessidade que a planta tem da segunda adubação, já citado, para seu fortalecimento e crescimento e pela semente para o plantio ser mais dispendiosa que as outras culturas, pela série de aperfeiçoamentos e melhoramentos feitos pela transgenia. Outro fator relevante é a compra de insumos na quantidade certa e, como a plantação é feita em poucos hectares, o poder de negociação de compra de insumos se torna complicada se comparar com agricultores que compram e maior quantidade, pela questão de descontos e prazos para pagamento.

\subsection{Resultados Totais e Indicadores de Volume}

Os indicadores de volume são determinantes na análise da propriedade rural, é a partir deles que os proprietários podem analisar quanto cada atividade colabora para a propriedade e qual a quantidade mínima de produção que a propriedade necessita possuir.

Verificando o quadro 02, o custo por hectare na atividade de soja, milho e leiteira é de $\mathrm{R} \$ 1.710,77, \mathrm{R} \$ 2.441,54$ e $\mathrm{R} \$ 2.292,86$ respectivamente. O custo unitário por saca de soja apresentou $\mathrm{R} \$ 34,22$, para a saca de milho apresentou $\mathrm{R} \$ 20,35$ e para a produção leiteira apresentou $\mathrm{R} \$ 0,68$.

Quadro 02-Resultado Total e Indicadores de Volume - 2016/2017

\begin{tabular}{|c|c|c|c|}
\hline \multirow{2}{*}{ Descrição } & \multicolumn{3}{|c|}{ Resultado total e indicadores de volume } \\
\hline & Soja & Milho & Leite \\
\hline Custo hectare & $1.710,77$ & $2.441,54$ & $2.292,86$ \\
\hline Produção total & 500 & 1.200 & 33.899 \\
\hline Custo unitário & 34,22 & 20,35 & 0,68 \\
\hline Preço venda & 70 & 25 & 1,32 \\
\hline Receita bruta total & $35.000,00$ & $30.000,00$ & $44.687,81$ \\
\hline Receita líquida total & $34.195,00$ & $29.310,00$ & $43.659,99$ \\
\hline Custo total & $17.107,74$ & $24.415,36$ & $22.928,64$ \\
\hline Resultado líquido total & $\mathbf{1 7 . 0 8 7 , 2 6}$ & $4.894,64$ & $20.731,35$ \\
\hline Resultado por há & $1.708,73$ & 489,46 & $2.073,13$ \\
\hline Resultado bruto por há & $3.500,00$ & $3.000,00$ & $4.468,78$ \\
\hline Custo variável por há & $1.451,82$ & $2.306,19$ & $2.120,32$ \\
\hline Funrural - $(2,3 \%)$ & 80,5 & 69 & 102,78 \\
\hline MC por há & $1.967,68$ & 624,81 & $2.245,68$ \\
\hline MC por saca/litros & 39,35 & 5,21 & 0,66 \\
\hline PE em sacas/litros & 66 & 260 & 2.605 \\
\hline PE em reais & $4.606,10$ & $6.498,46$ & $3.433,69$ \\
\hline MSO & 434 & 940 & 31.294 \\
\hline MSO \% & $87 \%$ & $78 \%$ & $92 \%$ \\
\hline
\end{tabular}

Fonte: Dados extraídos da pesquisa realizada (2017)

A produção total de soja foi de 500 sacas, de milho $\mathrm{R} \$ 1.200$ sacas e 33.899 litros de leite, considerando na atividade leiteira o período de seis meses. O preço de comercialização 
da soja foi de $\mathrm{R} \$ 70,00$, do milho $\mathrm{R} \$ 25,00$, e da produção leiteira foi feita uma média do preço pago para o litro de leite nos seis meses de análise, outubro de 2016 a março de 2017, o que resultou em $\mathrm{R} \$ 1,32$.

Da receita líquida total descontando o Funrural resultou em $\mathrm{R} \$ 34.195,00$ para a soja, $\mathrm{R} \$ 29.310,00$ para o milho e $\mathrm{R} \$ 43.659,99$ para o leite, diminuindo o custo total, o resultado líquido total resultou em $\mathrm{R} \$ 17.087,26$ para soja, $\mathrm{R} \$ 4.894,64$ para o milho e $\mathrm{R} \$ 20.731,35$ para o leite. Salienta-se que o preço do milho na época da venda era considerado baixo se comparado com outros períodos, esse foi um dos fatores que interferiu no resultado final desta cultura.

Assim, analisando o resultado de um hectare, pode-se verificar que na cultura da soja, apresentou $\mathrm{R} \$ 1.708,73$, na cultura de milho $\mathrm{R} \$ 489,46$ e na produção de leite $\mathrm{R} \$ 2.073,13$. Verifica-se que o custo variável para uma saca de soja é de $\mathrm{R} \$ 29,04$, para um saco de milho $\mathrm{R} \$ 19,22$ e para um litro de leite $\mathrm{R} \$ 0,63$. Para o Funrural $\mathrm{R} \$ 1,61, \mathrm{R} \$ 0,58$ e $\mathrm{R} \$ 0,03$ respectivamente. Sendo, portanto mais rentável a produção de leite e em seguida a soja, se comparado com a cultura de milho.

Analisando a margem de contribuição, constata-se que a produção mais rentável e que contribui para o resultado é a atividade leiteira com $\mathrm{R} \$ 2.245,68$. De acordo com o ponto de equilíbrio, a propriedade precisa vender 66 sacas de soja, 260 sacas de milho e 2.605 litros de leite para cobrir os custos e despesas variáveis e fixas da propriedade. A margem de segurança para a cultivar soja é 434 sacas, para a cultivar milho 940 e para a produção leiteira 31.294 litros. Portanto a produção leiteira apresenta a maior margem de segurança operacional com $92 \%$ para a propriedade.

\subsection{Indicadores Econômico-Financeiros}

Para verificar em quanto tempo os investimentos que a propriedade efetuou no ano de 2016/2017 retornam para a propriedade demonstra-se os investimentos, projeta-se o fluxo de caixa, calcula-se os indicadores e analisa-se os resultados.

Observa-se no quadro 03 os investimentos que os proprietários da Fazenda ZP realizaram no ano de 2016, foi adquirido um trator e uma plantadeira pelo programa mais alimento no ano de 2013, assim o produtores obtiveram três anos de carência para ambos financiamentos, com juros de $2 \%$ a.a, no entanto o prazo para pagamento do trator é dez anos e para a plantadeira em sete anos. Ainda, foi adquirido um pulverizador no final do ano de 2016, onde a compra foi realizada com a primeira parcela a vista e as demais divididas em três parcelas anuais, ou seja, $\mathrm{R} \$ 5.000,00$ para cada ano no total de quatro.

Quadro 03-Investimentos
\begin{tabular}{|l|r|}
\hline \multicolumn{1}{|c|}{ Investimentos Soja e Milho } & R\$ \\
\hline Financiamento - Trator & $75.600,00$ \\
\hline Financiamento - Plantadeira & $25.000,00$ \\
\hline Compra primeira parcela a vista e o restante dividido em três parcelas anuais - Pulverizador & $20.000,00$ \\
\hline Total & $\mathbf{1 2 0 . 6 0 0 , 0 0}$ \\
\hline Investimentos Leite & $2.000,00$ \\
\hline Financiamento - Ordenhadeira & $3.000,00$ \\
\hline Financiamento - Resfriador & \\
\hline
\end{tabular}


Financiamento -Curral

Total

Total geral

Fonte: Dados extraídos da pesquisa realizada (2017)

$\mathrm{Na}$ atividade leiteira, os investimentos somam um total de $\mathrm{R} \$ 10.000,00$, onde o financiamento era em benefício a atividade leiteira, por esse fato os juros eram menores com prazo de carência de um ano e com período de dez anos para pagamento, com este valor foi comprado uma ordenhadeira no valor de $\mathrm{R} \$ 2.000,00$, um resfriador no valor de $\mathrm{R} \$ 3.000,00$ e a reforma do curral para a ordenha das vacas que totalizou $\mathrm{R} \$ 5.000,00$. Cabe salientar que no ano de 2016 todos esses financiamentos foram efetuados em prol do melhoramento de cada atividade e aumentar a rentabilidade e qualidade da propriedade.

Quadro 04-Projeção de Fluxo de Caixa para 10 anos - 2016/2025

\begin{tabular}{|c|c|c|c|c|c|c|}
\hline \multicolumn{7}{|c|}{ Fluxo de caixa 10 anos } \\
\hline Anos & $\mathbf{0}$ & 2016 & 2017 & 2018 & 2019 & 2020 \\
\hline Ingressos & & 138.077,27 & $138.077,27$ & 138.077,27 & $138.077,27$ & $138.077,27$ \\
\hline Receitas de venda de soja & & $35.000,00$ & $35.000,00$ & $35.000,00$ & $35.000,00$ & $35.000,00$ \\
\hline Receitas de venda de milho & & $30.000,00$ & $30.000,00$ & $30.000,00$ & $30.000,00$ & $30.000,00$ \\
\hline Receita de venda de leite & & $61.927,81$ & $61.927,81$ & $61.927,81$ & $61.927,81$ & $61.927,81$ \\
\hline Receita venda de novilhos & & $14.400,00$ & $14.400,00$ & $14.400,00$ & $14.400,00$ & $14.400,00$ \\
\hline Funrural & & $-3.250,54$ & $-3.250,54$ & $-3.250,54$ & $-3.250,54$ & $-3.250,54$ \\
\hline Desembolsos & & $114.215,37$ & $113.974,93$ & $113.734,50$ & 113.494,07 & $108.253,64$ \\
\hline Custos totais & & $81.390,58$ & $81.390,58$ & $81.390,58$ & $81.390,58$ & $81.390,58$ \\
\hline Custo com novilhos & & $13.611,58$ & $13.611,58$ & $13.611,58$ & $13.611,58$ & $13.611,58$ \\
\hline Financiamentos & & $17.131,43$ & $17.131,43$ & $17.131,43$ & $17.131,43$ & $12.131,43$ \\
\hline Juros financeiros & & $2.081,78$ & $1.841,35$ & $1.600,92$ & $1.360,48$ & $1.120,05$ \\
\hline Investimentos & $-130.600,00$ & & & & & \\
\hline SALDO DE CAIXA ANUAL & $-130.600,00$ & $23.861,90$ & $24.102,34$ & $24.342,77$ & $24.583,20$ & $29.823,63$ \\
\hline SALDO INICIAL & $-130.600,00$ & $-130.600,00$ & $-106.738,10$ & $-82.635,76$ & $-58.292,99$ & $-33.709,79$ \\
\hline SALDO FINAL DE CAIXA & $-130.600,00$ & $-106.738,10$ & $-82.635,76$ & $-58.292,99$ & $-33.709,79$ & $-3.886,15$ \\
\hline Anos & & 2021 & 2022 & 2023 & 2024 & 2025 \\
\hline Ingressos & & 138.077,27 & 138.077,27 & 138.077,27 & 138.077,27 & 138.077,27 \\
\hline Receitas de venda de soja & & $35.000,00$ & $35.000,00$ & $35.000,00$ & $35.000,00$ & $35.000,00$ \\
\hline Receitas de venda de milho & & $30.000,00$ & $30.000,00$ & $30.000,00$ & $30.000,00$ & $30.000,00$ \\
\hline Receita de venda de leite & & $61.927,81$ & $61.927,81$ & $61.927,81$ & $61.927,81$ & $61.927,81$ \\
\hline Receita venda de novilhos & & $14.400,00$ & $14.400,00$ & $14.400,00$ & $14.400,00$ & $14.400,00$ \\
\hline Funrural & & $-3.250,54$ & $-3.250,54$ & $-3.250,54$ & $-3.250,54$ & $-3.250,54$ \\
\hline Desembolsos & & $108.013,20$ & $107.772,77$ & $103.993,35$ & $103.823,70$ & $103.654,05$ \\
\hline Custos totais & & $81.390,58$ & $81.390,58$ & $81.390,58$ & $81.390,58$ & $81.390,58$ \\
\hline Custo com novilhos & & $13.611,58$ & $13.611,58$ & $13.611,58$ & $13.611,58$ & $13.611,58$ \\
\hline Financiamentos & & $12.131,43$ & $12.131,43$ & $8.560,00$ & $8.560,00$ & $8.560,00$ \\
\hline Juros financeiros & & 879,62 & 639,19 & 431,19 & 261,54 & 91,89 \\
\hline Investimentos & $-130.600,00$ & & & & & \\
\hline SALDO DE CAIXA ANUAL & $-130.600,00$ & $30.064,07$ & $30.304,50$ & $34.083,92$ & $34.253,57$ & $34.423,22$ \\
\hline SALDO INICIAL & $-130.600,00$ & $-3.886,15$ & $26.177,92$ & $56.482,41$ & $90.566,33$ & $124.819,90$ \\
\hline SALDO FINAL DE CAIXA & $-130.600,00$ & $26.177,92$ & $56.482,41$ & $90.566,33$ & $124.819,90$ & $159.243,12$ \\
\hline
\end{tabular}

Fonte: Dados extraídos da pesquisa realizada (2017)

Após a análise dos custos, receitas, investimentos e indicadores de volume, projeta-se o fluxo de caixa para dez anos, levando-se em consideração os financiamentos efetuados que

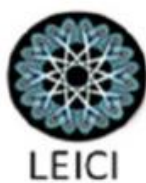


vão levar em média dez anos para quitá-los, projetou-se um fluxo de 2016 a 2025 com os valores de receitas e custos inalterados, e para os financiamentos e juros suas respectivas variações de um ano para o outro, demonstrando em que período a propriedade obtém saldo de caixa positivo.

Constatou-se conforme o quadro 04 , que as receitas anuais compreendem a venda de 500 sacas de soja ao preço de $\mathrm{R} \$ 70,00$, a venda de 1.200 sacas de milho ao preço de $\mathrm{R} \$$ 25,00 e 52.399 litros de leite ao preço que varia de $R \$ 0,90$ a $R \$ 1,39$, fator quantidade e qualidade que direciona o preço do leite. A propriedade também possui venda de novilhos, que os próprios proprietários criam, estes são os bezerros que nascem das vacas, se tornam novilhos que são engordados e destinados para venda. Em média a propriedade possui 10 novilhos prontos para venda, pesando de 120 a 150 quilos e recebendo por cabeça, $\mathrm{R} \$ 12,00$. Das receitas brutas se deduz o Funrural, o imposto que os agricultores pagam a cada produto comercializado, assim os ingressos totais no ano são de $\mathrm{R} \$ 138.077,27$ para a propriedade.

Os desembolsos são compostos pelos custos das três atividades, como o plantio de soja e milho é feito uma vez ao ano, os custos somam-se aos custos do leite, multiplicados por duas vezes, visto que antes o cálculo era os custos para meio ano, totalizando assim, R\$ 81.390,58. Os custos com os novilhos são calculados para 10 cabeças de bezerros e 10 cabeças de novilhos e totalizam $\mathrm{R} \$ 13.611,58$. Os pagamentos dos financiamentos e seus respectivos juros tem início no ano de 2016, observando que os financiamentos foram calculados pela tabela SAC (sistema de amortização constante), assim o valor da amortização é fixa e o valor dos juros diminui a cada mês, fazendo com que as parcelas sejam diminutivas a cada ano que se passa.

O total dos investimentos totaliza $\mathrm{R} \$ 130.600,00$ que são investidos em maquinários, equipamentos, implementos e infraestrutura da propriedade. O total de caixa em 2016 corresponde a $\mathrm{R} \$ 23.861,90$ e em $2025 \mathrm{R} \$ 34.423,22$, verificando o aumento do saldo de caixa a cada ano. E o saldo de caixa final em 2016 corresponde em $\mathrm{R} \$-106.738,10$ e em 2025 $\mathrm{R} \$ 159.243,12$.

É de suma importância para a propriedade saber em quanto tempo os investimentos que foram realizados, retornam para a propriedade, no caso particular desta propriedade todos os maquinários adquiridos foram de forma substitutiva, para facilitar o trabalho dos agricultores em seu manejo do dia-a-dia e poder adquirir arrendamentos. Salientando-se que o pulverizador foi abatido o valor da venda na compra do novo em forma de negociação. E na atividade leiteira, o resfriador foi substituído, a ordenhadeira foi comprada, já que a propriedade não possuía e a reforma foi necessária para melhorar a infraestrutura geral e receber a mecanização.

Quadro 05 -Indicadores Econômico-Financeiros para 10 anos - 2016/2025

\begin{tabular}{|c|r|r|r|}
\hline \multicolumn{5}{|c|}{ Payback descontado } \\
\hline Anos & Fluxo de caixa & Valor Presente & Saldo \\
\hline $\mathbf{0}$ & $-130.600,00$ & $-130.600,00$ & $-109.850,52$ \\
\hline $\mathbf{1}$ & $23.861,90$ & $20.749,48$ & $-91.625,69$ \\
\hline $\mathbf{2}$ & $24.102,34$ & $18.224,83$ & $-75.619,92$ \\
\hline $\mathbf{3}$ & $24.342,77$ & $16.005,77$ & $-61.564,40$ \\
\hline $\mathbf{4}$ & $24.583,20$ & $14.055,53$ & \\
\hline
\end{tabular}




\begin{tabular}{|c|r|r|r|}
$\mathbf{5}$ & $29.823,63$ & $14.827,62$ & $-46.736,78$ \\
\hline $\mathbf{6}$ & $30.064,07$ & $12.997,53$ & $-33.739,25$ \\
\hline $\mathbf{7}$ & $30.304,50$ & $11.392,58$ & $-22.346,67$ \\
\hline $\mathbf{8}$ & $34.083,92$ & $11.142,09$ & $-11.204,58$ \\
\hline $\mathbf{9}$ & $34.253,57$ & $9.737,00$ & $-1.467,57$ \\
\hline $\mathbf{1 0}$ & $34.423,22$ & $8.508,89$ & $7.041,32$ \\
\hline VPL & & $\mathbf{7 . 0 4 1 , 3 2}$ & \\
\hline TMA & \multicolumn{3}{|c|}{$\mathbf{1 5 \%}$} \\
\hline TIR & \multicolumn{3}{|c|}{$\mathbf{1 6 \%}$} \\
\hline Payback & \multicolumn{3}{|c|}{ 9 anos e 2 meses } \\
\hline
\end{tabular}

Fonte: Dados extraídos da pesquisa realizada (2017)

Analisando os resultados dos indicadores de viabilidade apurados no quadro 05, verifica-se que os fluxos de caixa se apresentam negativos até o nono ano de atividade, assim, a partir do décimo ano que o fluxo se torna positivo, com o valor presente líquido em $\mathrm{R} \$$ 7.041,32.

A TMA, taxa mínima de atratividade para a propriedade foi estipulada em $10 \%$ para a remuneração dos proprietários, já que não foi considerada a remuneração dos mesmos nos desembolsos da propriedade, $3 \%$ para o risco da atividade e $2 \%$ pelas taxas de juros bancárias que os investimentos realizados pela propriedade foram pagos, considerando uma TMA de $15 \%$.

A TIR foi calculada e resultou em $16 \%$, portanto, como a mesma é superior que a TMA, a propriedade está em viabilidade. O payback é a quantidade de tempo que um investimento leva para trazer retorno para a propriedade, em 9 anos e 2 meses os investimentos de $\mathrm{R} \$ 130.600,00$ são recuperados.

Verifica-se no quadro 06 o mix de produção da propriedade, importante para o gerenciamento da mesma.

Fazendo uma análise comparativa e com o intuito de verificar a sustentabilidade da propriedade, analisou-se a atividade mais rentável, a atividade leiteira, e fez-se a comparabilidade entre a cultivar soja e milho.

\section{Quadro 06 - Sustentabilidade para a Propriedade}

\begin{tabular}{|l|r|r|r|}
\hline & \multicolumn{3}{|c|}{ Sustentabilidade da propriedade } \\
\hline & Soja & Milho & Leite \\
\hline Margem Contribuição Total & $19.676,78$ & & \\
\hline \\
Hectares adicionais & $\mathbf{1 1}$ & $6.248,07$ & \\
\hline Prova real & $22.456,78$ & $\mathbf{3 6}$ & \\
\hline
\end{tabular}

Fonte: Dados extraídos da pesquisa realizada (2017)

Verificou-se em quantas hectares a propriedade precisaria produzir a mais para atingir a mesma margem que o leite apresenta. Com isso, necessitaria produzir 11 hectares adicionais da cultivar soja e 36 hectares da cultivar milho.

Para verificar qual é o resultado líquido para cada atividade, elabora-se a Demonstração do Resultado do Exercício. Segundo Basso (2011) essa demonstração apresenta as diversas fases do resultado, demonstrando a formação do resultado do exercício, 
a partir da importante análise das receitas e suas deduções, custos e resultado, lucro ou prejuízo da entidade.

Quadro 07 -Demonstração do Resultado

\begin{tabular}{|l|r|r|r|}
\hline \multicolumn{2}{|c|}{ Demonstração do Resultado - 6 meses } \\
\hline \multicolumn{1}{|c|}{ Descrição } & \multicolumn{1}{c|}{ Leite } & \multicolumn{1}{c|}{ Soja } & \multicolumn{1}{c|}{ Milho } \\
\hline Receita Operacional Bruta & $\mathbf{4 4 . 6 8 7 , 8 1}$ & $\mathbf{3 5 . 0 0 0 , 0 0}$ & $\mathbf{3 0 . 0 0 0 , 0 0}$ \\
\hline Venda produção & $44.687,81$ & $35.000,00$ & $30.000,00$ \\
\hline Dedução da Receita Operacional Bruta & $\mathbf{1 . 0 2 7 , 8 2}$ & $\mathbf{8 0 5 , 0 0}$ & $\mathbf{6 9 0 , 0 0}$ \\
\hline Funrural - 2,3\% & $1.027,82$ & 805,00 & 690,00 \\
\hline Receita Operacional Líquida & $\mathbf{4 3 . 6 5 9 , 9 9}$ & $\mathbf{3 4 . 1 9 5 , 0 0}$ & $\mathbf{2 9 . 3 1 0 , 0 0}$ \\
\hline Custo da produção & $21.220,55$ & $14.535,55$ & $23.079,26$ \\
\hline Depreciação & $1.708,09$ & $2.572,19$ & $1.336,09$ \\
\hline Despesas financeiras & 340,51 & 486,96 & 243,48 \\
\hline Lucro Operacional Líquido & $\mathbf{2 0 . 3 9 0 , 8 4}$ & $\mathbf{1 6 . 6 0 0 , 3 0}$ & $\mathbf{4 . 6 5 1 , 1 6}$ \\
\hline Resultado Líquido & $\mathbf{2 0 . 3 9 0 , 8 4}$ & $\mathbf{1 6 . 6 0 0 , 3 0}$ & $\mathbf{4 . 6 5 1 , 1 6}$ \\
\hline Resultado Líquido total & $\mathbf{4 1 . 6 4 2 , 3 1}$ & \multicolumn{3}{|c|}{} \\
\hline Resultado Líquido por atividade & $\mathbf{4 9 \%}$ & $\mathbf{4 0 \%}$ & $\mathbf{1 1 \%}$ \\
\hline Lucro por sacas/litros & $\mathbf{0 , 6 0}$ & $\mathbf{3 3 , 2 0}$ & $\mathbf{3 , 8 8}$ \\
\hline
\end{tabular}

Fonte: Dados extraídos da pesquisa realizada (2017)

Verifica-se no quadro 07 que o lucro operacional líquido para cada atividade corresponde em $\mathrm{R} \$ 20.390,84$ para a atividade leiteira, $\mathrm{R} \$ 16.600,30$ para a cultura da soja e $\mathrm{R} \$ 4.651,16$ para a cultura do milho. Correspondendo um resultado total de $\mathrm{R} \$ 41.642,31$, e deste $49 \%$ é resultado do leite, $40 \%$ da soja e $11 \%$ do milho, sendo que o lucro por litro de leite é $\mathrm{R} \$ 0,60$, para a soja, $\mathrm{R} \$ 33,20$ e para o milho $\mathrm{R} \$ 3,88$.

Por fim, cabe salientar que os custos variáveis, que se apresentaram mais relevantes neste estudo, não são definidos pelo produtor, ou seja, os mesmos não tem controle sobre o dólar, inflação, condições climáticas, importação, exportação, natureza de mercado e demais influências existentes. Assim verifica-se no quadro 08 uma simulação de variação de preços de venda, que é apenas uma das influências. Salienta-se que os preços utilizados para a simulação são considerados do dia 19 de dezembro de 2017.

Quadro 08 - Simulação - Influência Preço

\begin{tabular}{|l|r|r|r|}
\hline \multirow{2}{*}{ Descrição } & \multicolumn{3}{c|}{ Resultado total e indicadores de volume } \\
\cline { 2 - 4 } & \multicolumn{1}{|c|}{ Soja } & \multicolumn{1}{c|}{ Milho } & \multicolumn{1}{c|}{ Leite } \\
\hline Custo hectare & $1.710,77$ & $2.441,54$ & $2.292,86$ \\
\hline Produção total & 500 & 1.200 & 33.899 \\
\hline Custo unitário & 34,22 & 20,35 & 0,68 \\
\hline Preço venda & $\mathbf{5 9 , 5 0}$ & $\mathbf{2 6 , 0 0}$ & $\mathbf{0 , 9 7}$ \\
\hline Receita bruta total & $\mathbf{2 9 . 7 5 0 , 0 0}$ & $\mathbf{3 1 . 2 0 0 , 0 0}$ & $\mathbf{3 2 . 8 2 1 , 0 8}$ \\
\hline Receita líquida total & $\mathbf{2 9 . 0 6 5 , 7 5}$ & $\mathbf{3 0 . 4 8 2 , 4 0}$ & $\mathbf{3 2 . 0 6 6 , 2 0}$ \\
\hline Custo total & $17.107,74$ & $24.415,36$ & $22.928,64$ \\
\hline Resultado líquido total & $\mathbf{1 1 . 9 5 8 , 0 1}$ & $\mathbf{6 . 0 6 7 , 0 4}$ & $\mathbf{9 . 1 3 7 , 5 5}$ \\
\hline Resultado por há & $1.195,80$ & 606,70 & 913,76 \\
\hline Resultado bruto por há & $2.975,00$ & $3.120,00$ & $3.282,11$ \\
\hline
\end{tabular}




\begin{tabular}{|c|c|c|c|}
\hline Custo variável por há & $1.451,82$ & $2.306,19$ & $2.120,32$ \\
\hline Funrural - $(2,3 \%)$ & 68,43 & 71,76 & 75,49 \\
\hline MC por há & $1.454,75$ & 742,05 & $1.086,30$ \\
\hline MC por saca & 29,10 & 6,18 & $\mathbf{0 , 3 2}$ \\
\hline PE em sacas & 89 & 219 & 5.384 \\
\hline PE em reais & $5.295,62$ & $5.690,60$ & $5.213,86$ \\
\hline MSO & 411 & 981 & 28.515 \\
\hline MSO \% & $82 \%$ & $82 \%$ & $84 \%$ \\
\hline \multirow{2}{*}{ Descrição } & \multicolumn{3}{|c|}{ Sustentabilidade da propriedade } \\
\hline & Soja & Milho & Leite \\
\hline Margem Contribuição Total & $14.547,53$ & $7.420,47$ & $10.862,98$ \\
\hline Hectares adicionais & & 20 & 13 \\
\hline Prova real & & $14.547,53$ & $14.547,53$ \\
\hline
\end{tabular}

Fonte: Dados extraídos da pesquisa realizada (2017)

Percebe-se que a influência preço fez com que a soja seja a cultura mais rentável para a propriedade e a atividade leiteira depois desta, o inverso da situação da propriedade no estudo elaborado, assim necessitaria 20 hectares adicionais para o milho e 13 hectares para a produção leiteira. Essa é apenas uma influência, ressaltando que a atividade agrícola depende dessas influências para o sucesso em cada atividade desenvolvida.

\section{Considerações Finais}

A agricultura é muito importante para toda a cadeia produtiva, ela é a produtora dos alimentos que todos consomem. Com o advento da tecnologia, mecanização e transgenia os custos aumentam e se diversificam, assim a contabilidade no agronegócio é de extrema relevância para a geração de informação, tomada de decisão e gerenciamento das propriedades.

Com o objetivo de analisar os indicadores de resultados da cultura de soja, milho e produção leiteira na Fazenda ZP e propor a combinação das atividades que resultam o melhor resultado a propriedade, analisou-se os custos fixos e variáveis, diretos e indiretos de cada cultura. Observou-se que os custos diretos variáveis são mais representativos em todas as atividades, correspondendo aos insumos para as culturas de soja e milho e ração para a atividade leiteira. Dos custos variáveis e fixos, os custos variáveis tanto diretos e indiretos são mais representativos com $85 \%$ para a soja, $94 \%$ para o milho e $92 \%$ para o leite.

A cultura do milho apresentou o custo total mais representativo com $\mathrm{R} \$ 24.415,36$, consequentemente é a cultura que obteve o maior custo por hectare também. O custo maior por saca/litros foi apresentado para a cultura da soja, com $\mathrm{R} \$ 34,22$, isto porque o rendimento por hectare não foi muito satisfatório no ano de estudo, impactando assim no custo unitário, salienta-se que não apresenta prejuízo, já que o preço de venda foi considerado elevado, $\mathrm{R} \$$ 70,00 a saca. 
O maior resultado bruto e líquido por hectare foi apresentado pela atividade leiteira, seguido da soja. A atividade leiteira foi a que apresentou maior margem de contribuição por hectare, o menor ponto de equilíbrio e maior margem de segurança operacional.

Com os investimentos realizados na propriedade com compra de maquinários, implementos, equipamentos e melhoramentos na infraestrutura, realizou-se uma projeção de caixa para dez anos mantendo os ingressos e desembolsos iguais para esse período e constatou-se que o investimento é recuperado em 9 anos e 2 meses, com uma TIR de 16\%, superando a TMA de 15\%, com um VPL de $\mathrm{R} \$ 7.041,32$, portanto, o investimento é viável para a propriedade.

A resposta da questão problema foi alcançada a partir da análise dos resultados e indicadores de cada atividade, compôs-se a quantidade de hectares necessárias a se produzir, comparando com a atividade que apresentou melhor resultado, que no caso foi a atividade leiteira. Com o intuito de promover a sustentabilidade da propriedade, necessitaria produzir em 11 hectares adicionais de soja e em 36 de milho.

Por fim, a atividade leiteira foi a atividade que mais resultado gerou, isto porque seus resultados são mensais, enquanto que para a soja e o milho somente ocorre uma safra a cada ano. Salienta-se também que cada período muda, em função dos fatores climáticos, pragas, preços de venda e demais obstáculos são encontrados no meio agrícola, assim, uma cultura pode complementar a outra, visto assim a importância da propriedade ter mais de uma atividade e saber através da contabilidade qual é a mais rentável para estratégias futuras.

\section{Referências}

BASSO, I. P. Contabilidade geral básica. 4.ed.rev. Ijuí: Unijuí, 2011. 376p.

BEUREN, I. M. (ORG). Como elaborar trabalhos monográficos em contabilidade. 2.ed. São Paulo: Atlas, 2004. 195p.

CASAROTTO FILHO, N.; KOPITTKE, B. H. Análise de investimentos: matemática financeira, engenharia econômica, tomada de decisão, estratégia empresarial. 7. ed. São Paulo: Atlas, 1996. 448p.

CFC - Conselho Federal de Contabilidade. Resolução CFC n ${ }^{\circ} 1.136$ de 21.11.2008. NBC T 16.9 -Depreciação, Amortização e Exaustão.

CREPALDI, S. Contabilidade rural: uma abordagem decisorial.7.ed. São Paulo: Atlas, 2012. 397p.

DAVis, J. H.; GOldberG, R. A. A Concept of Agribusiness. Division of Research. Graduate School of Business Administration. Harvard University, 1957. 136p.

EMATER/RS-ASCAR. Informações agropecuárias: série histórica. Rio Grande do Sul: 2017. Disponível em: http://www.emater.tche.br/site/servicos/informacoesagropecuarias.php\#conjuntural. Acessado em: 18 de dezembro de 2017.

GIL, Antonio C. Métodos e técnicas de pesquisa social. 5.ed. São Paulo: Atlas, 1999. 206p. GITMAN, L. J. Princípios de administração financeira. 12.ed. São Paulo: Pearson Prentice Hall, 2010. 775p.

GUBERT, A. R.; BARRO, O. J.; PFÜLLER, E. E. Análise dos custos de produção de uma pequena propriedade rural no município de Getúlio Vargas RS. Revista de Administração e Ciências Contábeis do IDEAU - RACI. 5 vol. n.10. Janeiro - Junho 2010. Semestral.
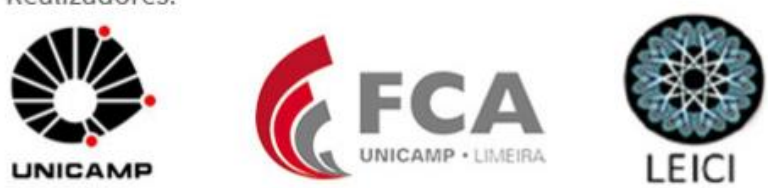
HALL, R. J. et al. Gestão de custo das empresas rurais produtoras de grãos.In: $2^{\circ}$ Congresso UFSC de Controladoria e Finanças \& Iniciação Científica em Contabilidade, 2008. Santa Catarina. Anais... Santa Catarina: 2008.

HOFER, E.; HUPPES, S. S. Gestão de custos como ferramenta de controle para a diversificação na pequena propriedade rural. In: XIV Congresso Brasileiro de Custos, 2007. Paraíba. Anais... Paraíba: 2007.

INSTITUTO BRASILEIRO DE GEOGRAFIA E ESTTÍSTICA - IBGE (Org). Censo Agropecuário, Rio de Janeiro: 2006. 777p.

KASSAI, J. R. et al. Retorno de investimento: abordagem matemática e contábil do lucro empresarial. 2. ed. São Paulo: Atlas, 2000. 256p.

MAGRO, C. B. D. et al. Contabilidade rural: comparativo na rentabilidade das atividades. In: XVIII Congresso Brasileiro de Custos, 2011. Rio de Janeiro.Anais... Rio de Janeiro: 2011. MARCONI, M. de A; LAKATOS, E. M. Fundamentos de metodologia científica.5.ed. São Paulo: Atlas, 2003. 311p.

MARION, J. C.; SEGATTI, S. Sistema de gestão de custos nas pequenas propriedades leiteiras. Custos e@ gronegócio on line,v. 2, n. 2, p. 6, 2002.

MARTINS, E. Contabilidade de custos. 8.ed. São Paulo : Atlas, 2001. 388p.

PADOVEZE, C. L. Curso básico gerencial de custos. São Paulo: Pioneira Thomson Learning, 2003. 377p.

PESENTE, R. et al.Comparabilidade econômico-financeira das atividades leiteira e avícola. In:XXIII Congresso Brasileiro de Custos, 2016. Pernambuco. Anais... Pernambuco: 2016.

PEREZ JR, J. H.; OLIVEIRA, L. M. DE; COSTA, R. G. Gestão estratégica de custos. 2.ed. São Paulo: Atlas, 2001. 312p.

SILVA, E. L. D.; MENEZES, E. M. Metodologia da pesquisa e elaboração de dissertação. 4. ed. Florianópolis: UFSC, 2005. 138 p.

SILVA, R. N. S.; LINS, L. D. S. Gestão de custos: contabilidade, controle e análise. São Paulo: Atlas, 2010. 249p.

SOUZA, A.; CLEMENTE, A. Gestão de custos: aplicações operacionais e estratégicas:exercícios resolvidos e propostos com utilização do Excel. 2 ed. São Paulo: Atlas, 2011. 266p.

SOUZA, A. et al. Custos de produção, expectativas de retorno e de risco para o agronegócio do milho na região do Planalto Norte-Catarinense. In: XVI Congresso Brasileiro de Custos, 2009.Ceará. Anais... Ceará: 2009.

SUSKI, M. I.; BRAUM, L. M. dos S.; BRAUN, R. S. Gestão de Custos: um estudo de caso em uma propriedade rural localizada na região Oeste do Estado do Paraná. In: XXI Congresso Brasileiro de Custos, 2014. Rio Grande do Norte. Anais... Rio grande do Norte: 2014.

YIN, R. K. Estudo de caso: planejamento e métodos. 2.ed. Porto Alegre: Bookman, 2001. $205 p$.

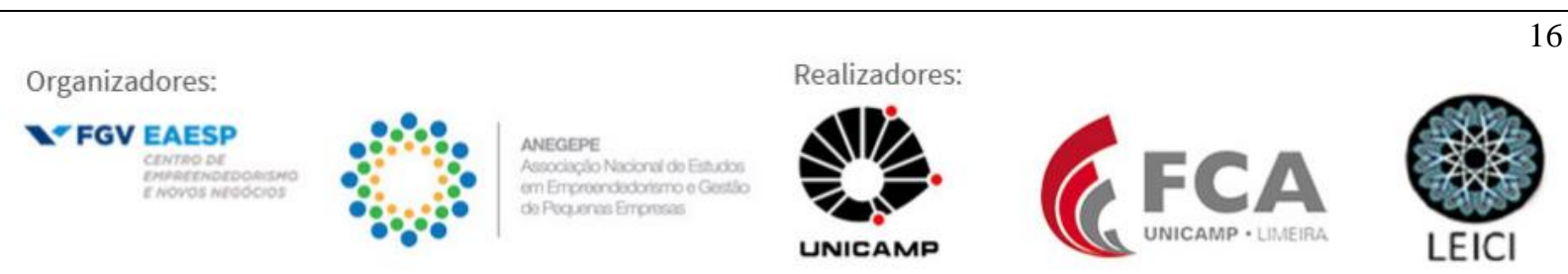

